\title{
Bladder Neck Involvement in Radical Prostatectomy Specimens is not a pT4 Disease
}

\author{
Radikal Prostatektomide Saptanan Mesane Boynu Invazyonu pT4 Değildir
}

Pelin Yıldız

Bezmialem Vakıf University Faculty of Medicine, Department of Pathology, Istanbul, Turkiye

\section{Introduction}

Prostatic carcinoma is the most common cancer in men in the USA and Europe. It is the second cause of cancer death among men (1). Bladder neck (BN) involvement (BNI) after radical prostatectomy has been a matter of debate for many years. In the fourth edition of the American Joint Committee on Cancer (AJCC) staging manual published in 1992, it was classified in pT4 category, showing the extension of the tumor into the adjacent organs such as the rectum, external sphincter or the pelvic wall musculature (2). Since then, several studies have been published discussing whether it should be classified as pT3 or pT4. Since BN sparing surgeries are preferred to avoid postoperative incontinence, it is important to make a proper substaging. In radical prostatectomy materials, there were many different BNI definitions. Consequently, it is classified as microscopic and macroscopic involvement (3). One of the two studies by Yossepowitch et al. (4) with a larger population cohort study with heterogeneous features, it was reported that sole BNI did not predict prostate-specific antigen (PSA) recurrence in a multivariate model and pT4 was suggested to be reserved for macroscopic or radiographic BNI instead of microscopic BNI. In their multiethnic, multicenter study, Buschemeyer et al. (5) concluded that a positive BN margin associated with other positive margins had a progression risk similar to seminal vesicle (SV) invasion (pT3b), however, an isolated BN margin was found to be a rare event. However, this data needs to be supported by large cohorts due to the limited number of patients. Additionally, patients with positive BN margin had higher PSA level, greater Gleason score, higher rates of extraprostatic extension (EPE), SV involvement, and positive surgical margins (5). Zhou et al.
(6) grouped microscopic BNI as true and false. True BNI had prostatic carcinoma within thick smooth muscle bundles without intermixed benign prostatic glands (Figure 1a), and false BNI had prostatic carcinoma intermixed with benign prostatic glands (Figure 1b). Regardless of this categorization, both groups had increased biochemical recurrence risk. According to this study, microscopic BNI should be staged between pT2 and pT3, and pT4 should be limited to gross or radiographic invasion, consistent with some of the previous studies (6). A large study (17000 patients) with a long time period (1982-2008) by Pierorazio et al. (7) supported the significance of a BNI after radical prostatectomy concordant with the study by Zhou et al. (6). They also used the true-false $\mathrm{BNI}$ term and found that biochemical recurrence-free and cancer-specific survival rates were similar to pT3a and pT3b,

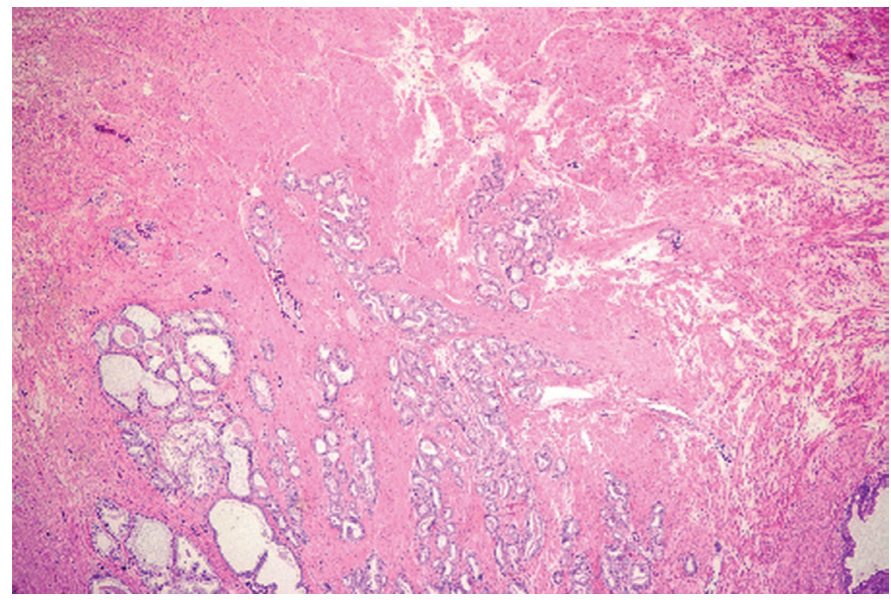

Figure 1a. True bladder neck involvement: Prostatic adenocarcinoma within thick smooth muscle bundles without intermixed benign prostatic glands (Hematoxylin-Eosin $\mathrm{x} 40$ )

Correspondence: Pelin Yıldız MD, Bezmialem Vakıf University Faculty of Medicine, Department of Pathology, i̇stanbul, Turkiye Phone: +90 5326031028 E-mail: drpelinyildiz@gmail.com ORCID ID: orcid.org/0000-0002-7709-7264 Received: 28.09.2017 Accepted: 29.09.2017

Cite this article as: Yıldız P. Bladder Neck Involvement in Radical Prostatectomy Specimens is not a pT4 Disease. J Urol Surg 2017;4:224-225.

๑Copyright 2017 by the Association of Urological Surgery / Journal of Urological Surgery published by Galenos Publishing House. 


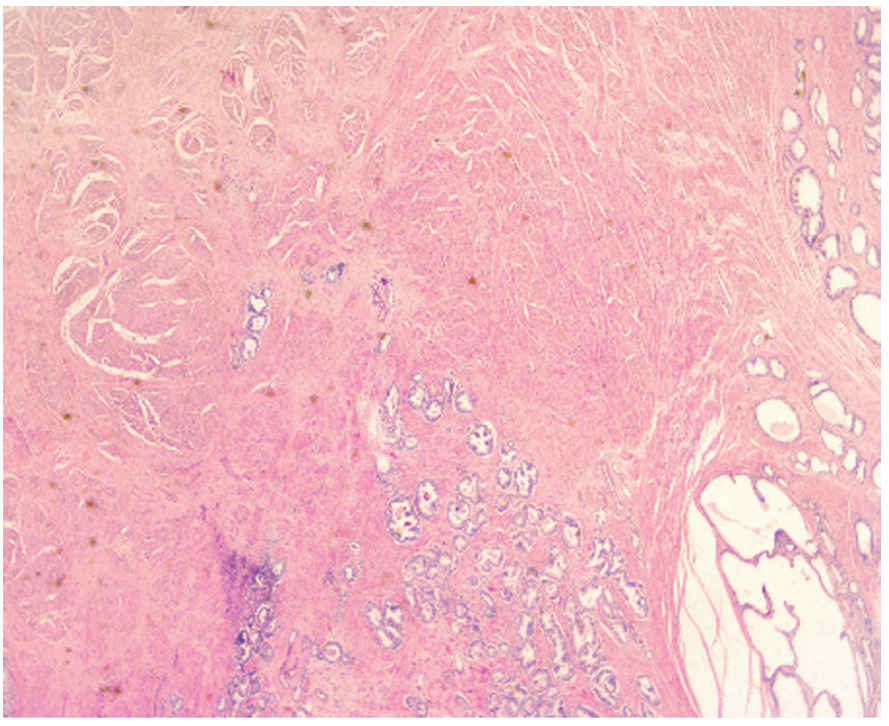

Figure 1b. False bladder neck involvement: Prostatic adenocarcinoma within thick smooth muscle bundles intermixed with benign prostatic glands (Hematoxylin-Eosin x40)

respectively. They also suggested that BNI could be settled into pT3a similar to EPE or placed into pT3b by pushing SV involvement to pT3c. The study emphasized that BNI should not be designated as stage $\mathrm{pT} 4$, in which the patients were rarely treated by surgery. On the contrary, this group of tumors can be resected or treated. This study also advocates their data's reliability with their quite large cohort and 25year single institution follow-up (7). After similar several studies, change was inevitable, and microscopic BNI was carried from pT4 to pT3a category in the seventh edition of the AJCC manual (3). Recently, a group of Korean urologists published a study supporting the validity of this change both in isolated positive BNI and BNI with another surgical margin positivity (8). After well designed and multiple large studies conducted with appropriate patient populations, BNI substaging remained the same in the $8^{\text {th }}$ edition of the AJCC manual (9). However, as both the prostate team of the AJCC and Silberstein and Eastham (10) mentioned, we still need further investigations to determine the significance of BNI substaging because of the rarity of this population.

\section{Acknowledgements}

Special thanks to Prof. Dr. Kutsal Yörükoğlu for redaction and the figures.

Keywords: Bladder, neck, involvement, pT4

Anahtar Kelimeler: Mesane, boyun, invazyon, pT4

\section{Ethics}

Peer-review: Externally peer-reviewed.

Financial Disclosure: The author declared that this study received no financial support.

\section{References}

1. Jemal $A$, Siegel $R$, Ward E, Hao $Y, X u$ J, Thun MJ. Cancer statistics, 2009. CA Cancer J Clin 2009;59:225-249.

2. Beahrs $\mathrm{OH}$, Henson DE, Hutter RVP, Kennedy BJ. American Joint Committee on Cancer Staging Manual for Staging of Cancer, 4th ed. Philadelphia, PA: Lippincott, 1992.

3. Edge SB, Byrd DR, Compton CC, et al. American Joint Committee on Cancer Staging Manual, 7th ed. New York, Springer, 2010.

4. Yossepowitch O, Sircar K, Scardino PT, Ohori M, Kattan MW, Wheeler TM Reuter VE. Bladder neck involvement in pathological stage pT4 radical prostatectomy specimens is not an independent prognostic factor. J Urol 2002;168:2011-2015.

5. Buschemeyer WC, Hamilton RJ, Aronson WJ, Presti JC Jr, Terris MK, Kane CJ, Amling CL, Freedland SJ. Is a positive bladder neck margin truly a T4 lesion in the prostate specific antigen era? Results from the SEARCH Database. J Urol 2008;179:124-129.

6. Zhou M, Reuther AM, Levin HS, Falzarano SM, Kodjoe E, Myles J, Klein E, Magi-Galluzzi C. Microscopic bladder neck involvement by prostate carcinoma in radical prostatectomy specimens is not a significant independent prognostic factor. Mod Pathol 2009;22:385-392.

7. Pierorazio PM, Epstein Jl, Humphreys E, Han M, Walsh PC, Partin AW. The significance of a positive bladder neck margin after radical prostatectomy: the American Joint Committee on Cancer PathologicalStage T4 designation is not warranted. J Urol 2010;183:151-157.

8. Chung MS, Lee SH, Lee DH, Chung BH. Evaluation of the 7th American Joint Committee on Cancer TNM Staging System for Prostate Cancer in Point of Classification of Bladder Neck Invasion. Jpn J Clin Oncol 2013;43:184-188.

9. Califano JA, Lydiatt WM, Nehal KS. AJCC Cancer Staging Manual, 8th ed. New York, NY, Springer, 2017.

10. Silberstein JL, Eastham JA. Significance and management of positive surgical margins at the time of radical prostatectomy. Indian J Urol 2014;30:423428. 